\title{
Una visita eclesiástica en zona de misiones: control y gobierno en el obispado de Maynas a inicios del siglo XIX*
}

\author{
An ecclesiastical visit in the mission area: attempts \\ of control and government in the bishopric of \\ Maynas at the beginning of the 19th century
}

\section{Elizabeth HERNÁNDEZ GARCÍA}

Universidad de Piura/Campus Lima

elizabeth.hernandez@udep.pe

\begin{abstract}
The bishopric of Maynas, which in general comprised the extensive northern Amazon of Peru, was the last created in the viceregal period (1802), with clear strategic, missionary and political objectives. An attempt was made to establish a strong diocese in a territory that had been distant both from the viceregal administration and from the collective imaginary in terms of population, geography and possibilities of development. In this context, the Bishop of Maynas, Hipólito Sánchez Rangel, through the ecclesiastical visit he made to his bishopric in the first decade of the 19th century and many other actions, was a political figure of great importance in the absence or distance of political instances that guaranteed the administration and control of one of the regions in which «Western civilization» had made little impact, a situation that was exacerbated by the process of independence of Peru. Sánchez Rangel is also a key figure for our understanding of that space; with his proposals for reform, he is one of the political actors - within the civil and ecclesiastical sphere- that sought to promote an improvement in different areas of Maynas and other areas within the Peruvian Amazon jungle.
\end{abstract}

Keywords: Bishop of Maynas; ecclesiastical visit; viceroyalty of Peru; northern Peru; Amazon rainforest, indigenous.
Resumen: El obispado de Maynas, que en general comprendía la extensa Amazonía norte del Perú, fue el último creado en la época virreinal (1802) con claros objetivos estratégicos, misionales y políticos que fortalecer. Se intentaba establecer una diócesis en un territorio que había estado distante tanto de la administración virreinal como del imaginario colectivo en cuanto a población, geografía y posibilidades de desarrollo. En este contexto, el obispo de Maynas, Hipólito Sánchez Rangel, a través de la visita eclesiástica que realizó a su obispado en la primera década del siglo XIX y de muchas otras acciones, fue una figura política de peso ante la ausencia, lejanía o inexistencia de instancias políticas que garantizasen la administración y el control de una de las regiones en las que la «civilización occidental» había llegado con poco éxito. Hipólito Sánchez Rangel se constituye, además, en una pieza clave para el conocimiento de la problemática de aquel espacio. Sus propuestas de reforma se insertan en un momento de tránsito entre la constitución de un nuevo obispado en una importante zona periférica, la debilidad del gobierno civil y la construcción del estado-nación pocos lustros antes de la independencia del Perú.

Palabras clave: Obispo de Maynas; visita eclesiástica; virreinato del Perú; norte del Perú; selva amazónica; indígenas.

* Este artículo se inserta dentro del proyecto de investigación «Justicia eclesiástica y conformación de la sociedad en la América Hispana colonial» (HAR2012-35197). 


\section{INTRODUCCIÓN}

El obispado de Maynas, creado en 1802, comprendía parte importante de la Amazonía peruana y territorios de las actuales repúblicas de Ecuador y Colombia. A lo largo de su historia fue una jurisdicción eclesiástica constituida por tierras de misiones de franciscanos, mercedarios y jesuitas, doctrinas y curatos que antes pertenecían a los obispados de Quito, Lima y Trujillo. La Real Cédula de 1802 que lo creó señaló a la nueva diócesis unos límites muy generales ${ }^{1}$, por ello es que la Corona encargó al obispo Hipólito Sánchez Rangel la tarea de hacer un mapa del nuevo espacio eclesiástico ${ }^{2}$. Sánchez Rangel vino a ser obispo de un espacio cuyas dimensiones exactas eran desconocidas. Geográficamente, además, era un territorio de difícil acceso, considerado inhóspito y hostil, al que le faltaban caminos, que tenía hondas dificultades en la circulación de bienes, con una navegación que solo los nativos podían efectuar.

El territorio descrito era en sí mismo una muralla geográfica, pero también era un límite demográfico-poblacional. Ello se debía a varias razones, entre las que García Jordán destaca el poco interés de la Corona por tierras carentes de metales preciosos, un tipo de explotación económica que no propició la formación de poblados permanentes sino más bien el desplazamiento de colonos, y finalmente la resistencia indígena a los invasores ${ }^{3}$. A estas razones se añaden las características de la población que conformaba el obispado de Maynas, la cual tenía niveles variopintos de «civilización». Desde la perspectiva de los evangelizadores y de la visión occidental en general, Maynas seguía siendo una zona de misión, con escasos y reducidos grupos de españoles y con un amplio grupo poblacional

1 «Al principio se le llamó obispado de Mainas porque se mandó que se erigiera en las misiones de Mainas y que se compusiera de todas las conversiones servidas por los misioneros de Ocopa y de la antigua Compañía de Jesús en los ríos Huallaga y Ucayali, con todas las montañas que sirven de entrada a ellos y que estaban en la jurisdicción del arzobispado de Lima. Se aplicaron también los curatos de Lamas, Moyobamba y Santiago de las Montañas, pertenecientes al obispado de Trujillo; todas las misiones de Mainas, los curatos de la provincia de Quijos excepto el de Pallacta; la doctrina de Canelos en el río Bombonaza, servida por padres dominicos; las misiones de religiosos mercedarios en la parte inferior del río Putumayo pertenecientes al obispado de Quito; y las misiones situadas en la parte superior del mismo río Putumayo y en el Yapurá, llamadas de Sucumbios, que estaban a cargo de los padres franciscanos de Popayán» (Carlos LARRABURE Y CORREA, Colección de leyes, decretos, resoluciones y otros documentos oficiales referentes al Departamento de Loreto, tomo III, Monumenta Amazónica, Iquitos [Perú], 2008, p. 163. [Primera edición, Lima, 1905]).

2 Ibid., p. 168.

3 Pilar García Jordán, Cruz y arado, fusiles y discursos. La construcción de los Orientes en el Perú y Bolivia 1820-1940, IFEA, IEP, Lima, 2001, p. 23. 


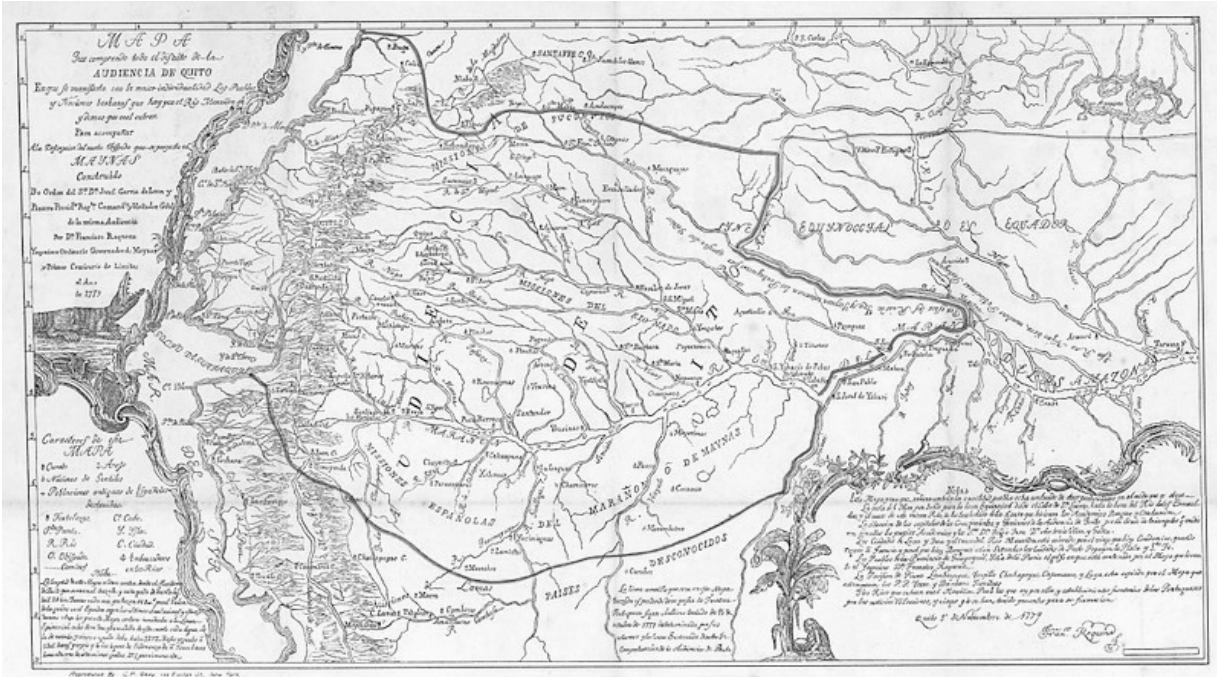

Mapa 1. «Mapa que comprende todo el distrito de la Audiencia de Quito. En que se manifiesta con la mayor individualidad los pueblos y naciones bárbaras que hay por el río Marañón y demás que en él entran. Para acompañar a la descripción del nuevo Obispado que se proyecta en MAYNAS. Construido de orden del Señor Don Josef García de León y Pizarro, Presidente Regente Comandante y Visitador General de la misma Audiencia, por Don Francisco Requena, Ingeniero Ordinario Gobernador de Maynas y primer Comisario de Límites, el año de 1779» Fuente:Wikimedia Commons. https://commons.wikimedia.org/wiki/File:Real_Audiencia_de_Quito_1779.jpg

indígena que seguir catequizando. En este sentido, Maynas era sinónimo de tribus, de «chunchos», de salvajes, de indios cazadores y recolectores en su gran mayoría, de «naciones incultas» por su grado de alfabetización, sus costumbres y su manera de vestirse y de pintarse los rostros ${ }^{4}$.

La mayor parte de la documentación publicada se refiere a la misión de Maynas en el tiempo de los jesuitas; pero esta misión era solo una de las que luego llegarían a conformar el obispado ${ }^{5}$, y corresponde propiamente al pe-

4 «Es también muy general en Maynas el uso de pintarse, como lo es en el Ucayali, y generalmente entre todas las Naciones incultas de esta América...» (Carta del señor Don Francisco Requena, gobernador de los Maynas, al R.P. Guardián de Ocopa con algunas reflexiones referentes al mejor gobierno y progresos de las Misiones del Ucayali, en Mercurio Peruano, edición facsimilar, tomo IX, 1793, fol. 5).

5 «Aunque el nombre de Maynas en rigor solo debió aplicarse a la comarca del N. del Marañón donde vivían dichos indios, se fue extendiendo después a todas las Misiones de la Compañía en la dilatada zona de la cuenca del Marañón o Amazonas» (Ricardo BELTRÁN RÓZPIDE, Maynas, Publicaciones de la Real Sociedad Geográfica, Imprenta del Patronato de Huérfanos de Intendencia e Intervención Militares, Madrid, 1911, p. I). 
ríodo anterior a su conformación. Para elaborar este trabajo ha sido preciso consultar los siguientes archivos: General de Indias, General de la Nación de Lima, Arzobispal de Lima y Arzobispal de Chachapoyas, ciudad esta última que desde 1831 es sede del obispado del mismo nombre y que incorporó el anterior de Maynas ${ }^{6}$.

A partir de la documentación de archivo, tenemos noticia de que la visita eclesiástica a este obispado se desarrolló entre los años 1807 y 18147. La realizaron el obispo y los visitadores del clero secular y regular nombrados por aquel. No se ha encontrado la visita completa del obispado de Maynas, sino partes dispersas en distintos legajos que no necesariamente tienen la catalogación idónea, hecho que ha dificultado la indagación. Paralelamente, nos hemos servido de los informes que el obispo redactó durante y después de su gobierno en Perú, Brasil y España. En estos informes, Sánchez Rangel da cuenta de todo lo que visitó, conoció e hizo por la diócesis.

En las siguientes páginas analizaremos los problemas centrales del obispado de Maynas que dificultaban o impedían, según la perspectiva del obispo, un proceso continuado en la evangelización y en el posicionamiento del estado y de la iglesia en esta región. Junto con esto, daremos cuenta de la importancia creciente del obispo de Maynas que, a fines de la colonia y en las dos primeras décadas del siglo XIX, cumplió funciones de control del territorio dentro de la tarea de conquista del espacio amazónico que había acometido la Corona para esta época. La visita eclesiástica fue un instrumento para ello, a partir de la cual el obispo planteó maneras para reorganizar el territorio, reordenar la jurisdicción eclesiástica y gobernar mejor -también en lo civil- un obispado peculiar que, en cuanto a su formación como tal, consideraba un espacio no bien calculado.

6 En Chachapoyas prácticamente no hay archivo eclesiástico sino repositorio de documentos. Si bien existe un incipiente catálogo documental, el lugar no cuenta con infraestructura para atender a los investigadores. En la actualidad está en marcha un proyecto de digitalización de una parte de la documentación del obispado de Chachapoyas, coordinado por Melecio Tineo Morón, director del Archivo Arzobispal de Huacho (Lima). Fuente: https://archivohuacho.wordpress. com/2019/01/20/proyecto-de-digitalizacion-en-el-archivo-del-obispado-de-chachapoyas/?fbcli d=IwAR3BfSuQr4cvWHdseTnZyLpHgEmz4VGF2ZhY3eqIsiMtBzj1dznx8jkyVuw (consultado el 26/02/2019).

7 Según José Barletti, el obispo realizó la visita entre los años 1808 y 1811. José BARLETTI, $L a$ población de Maynas en tiempos de la independencia: análisis de Lagunas y feberos, Documento Técnico n. ${ }^{\circ}$, Instituto de Investigaciones de la Amazonía peruana, Iquitos, 1994, p. 9. 


\section{«ESTE OBISPADO INCOMPRENSIBLE, Y SOLO CONOCIDO POR ELEVACIÓN Y POR CÁLCULO»8}

Desde el inicio de la colonización española, la selva fue mayormente «conquistada» por las órdenes religiosas. Son famosas, por ejemplo, las misiones y reducciones de los franciscanos que, desde el convento de Santa Rosa de Ocopa, controlaban algunos territorios, así como también las misiones y reducciones de los jesuitas. A pesar de estos y otros esfuerzos, en la selva amazónica lo que existía en todo caso era un estado colonial poco presente, en donde el clero, la Iglesia, era una representación o extensión del poder político, ya que llegaba a puntos donde aquel no podía arribar'.

La Corona acometió la tarea de una mayor presencia políticamente organizada en la selva en 1802 con la creación de la comandancia general de Maynas, configuración política que supuso para el Perú recuperar el territorio de la selva norte que había sido adjudicado al virreinato de Nueva Granada cuando este fue creado. Pero más que eso, lo importante a destacar es que por esta misma real cédula de 1802 también se creaba el obispado de Maynas ${ }^{10}$. Con esta nueva reforma se intentaba subsanar un gran problema, esto es el nulo control que desde el virreinato de Nueva Granada se tenía de las poblaciones de la selva norte peruana, problemática a la que se había sumado la expulsión de los jesuitas y el abandono de las misiones de esa parte del Perú. Con estas nuevas acciones, el estado intentaba ocupar política y eclesiásticamente un territorio y una población desconocida en gran medida. El primer nombramiento de obispo de Maynas recayó en Juan Antonio Mantilla, quien renunció a él. Por ello fue elegido en 1804 el franciscano Hipólito Sánchez Rangel y Fayas $^{11}$, quien se encargó del obispado hasta 1821, fecha en la que huye de su diócesis por temor a ser capturado por las fuerzas patriotas, como había ocurrido con José Carrión y Marfil, obispo de Trujillo del Perú. Sánchez Rangel no era partidario de la independencia, razón por la que se refugió en Brasil y luego partió rumbo a la metrópoli. A pesar de algún intento aprovechando el

8 Hipólito SÁNCHEZ RANGEL, Pastoral religioso-política, geográfica, Imprenta de Pujol, Lugo, 1827, p. 4.

9 Pilar GARCÍA Jordán, Iglesia y poder en el Perú contemporáneo 1821-1919, Cusco, Centro de Estudios Regionales Andinos «Bartolomé de las Casas», sf., p. 53.

10 Veáse, Luis Antonio Eguiguren EsCudero, Apuntes sobre la cuestión internacional entre el Perú y Ecuador, vol. 1, Maynas, Lima, 1941.

11 Carlos LarRabURe y CORREA, op. cit., tomo I, p. 164. 
siguiente y momentáneo triunfo realista en la selva norte, Sánchez Rangel no volvió a Maynas ${ }^{12}$.

Tal parece que en este momento, más importante que la comandancia general de Maynas fue el obispado y el primer obispo, pues a este se le atribuyeron funciones de vigilancia y control del territorio. Ello es evidente, por ejemplo, en la real cédula de 1805, en la cual se encargaba a Sánchez Rangel la tarea de elaborar un mapa de su diócesis ${ }^{13}$. Sin embargo, dicho encargo tuvo como obstáculos las propias autoridades eclesiásticas del virreinato del Perú, quienes no querían prescindir de curatos que antes habían estado bajo su administración, y que por la real cédula de 1802 tenían que pasar a Maynas. Esto generó tantos desencuentros que el obispo remitió una carta al Consejo de Indias, en septiembre de 1814, donde expuso que:

...no había podido arreglar los límites de su diócesis según la Bula de su erección por la resistencia que había encontrado en los Prelados limítrofes; pues ni ese muy reverendo obispo [Lima] le había querido entregar el pueblo de Santa María del Valle, ni los reverentes obispos de Huamanga y Trujillo los de Huanta y Rioja $^{14}$.

Estas rivalidades político-eclesiásticas fueron muy frecuentes entre el clero secular y el regular, las cuales el obispo de Maynas no pudo superar. De tal manera que nunca llegó a hacerse con el gobierno, en términos jurisdiccionales, de la totalidad del territorio que correspondía a su obispado. Paralelamente, en la práctica tampoco pudo abarcar físicamente toda su diócesis debido a las dificultades que la Amazonía peruana imponía:

12 Un interesante y detallado informe acerca de la situación de Maynas y de sus autoridades políticas, militares y eclesiásticas en la coyuntura de la independencia peruana, desde la perspectiva de quienes fueron partidarios de la contrarrevolución, es el documento elaborado por el secretario del obispo de Maynas: José María PADILLA Y ÁGUILA, Exposición económico política documentada de los sucesos ocurridos en el gobierno eclesiástico, civil y militar de las provincias de Mainas, invadidas por los disidentes del Perú en los años de 1820 y 1821, Madrid, Por don Antonio Fernández, 1823. Con una inclinación hacia la causa de la independencia, ver Alejandro ZUBIATE ZABARBURU, Contribución de Chachapoyas a la revolución emancipadora del Perú/ 1821-1824, Lima, 1974.

$13 \ll .$. que remitiréis al referido mi Consejo para su inteligencia, dándome cuenta ambos con la posible brevedad y la debida instrucción para las providencias que convengan al mayor fomento de esas misiones y mejor servicio de Dios y mío» (Carlos LARRABURE Y CORREA, op. cit., tomo I, p. 167-168).

14 ARCHIVO ARZOBISPAL DE LIMA (AAL). Serie: Documentos Jaén, Maynas y Chachapoyas, n. ${ }^{\circ}$ 14., año 1820 , fol. 2 
La porción de la grey que nos cupo en suerte se hallaba esparcida por montañas inaccesibles, a las márgenes de caudalosos ríos, poblaba los bosques, y habitaba con las fieras las grutas, y cortaduras de grandes desiertos, de distintos y encontrados climas, ásperas serranías, llanuras y ciénagas interminables ${ }^{15}$.

A la extensión del obispado, se añadían las dificultades en las comunicaciones, consecuencia de una geografía abrupta, variante, peligrosa inclusive, donde los recorridos incluían la navegación fluvial en ríos caudalosos de mucho peligro y retos. El clima por su parte favorecía la aparición de insectos de todo tipo, de enfermedades, de una fauna feroz, entre otros detalles que convertían a este espacio en un territorio inaccesible para muchos. Nos dice el obispo en su visita:

Las serranías... son inaccesibles... Las anduve a pie y descolgándome los indios con cuerdas en algunas partes. En Quijos, al bajar la montaña de Guacamayo, el río Cayumba... lo pasé en los hombros de los indios que iban nadando por no meterme en un canasto o tarabita que se veía en un palo atravesado por el río, temiendo no se quebraran las cuerdas que ya estaban podridas... ${ }^{16}$

Maynas en general se presentaba como inasible en los papeles oficiales y extraoficiales que circulaban en distintas esferas de gobierno. Mucha de esa documentación provenía de los miembros del clero, quienes brindaban datos relevantes sobre personas y lugares, proponiendo al mismo tiempo medidas que el gobierno civil debía tomar. Así, por ejemplo, el segundo obispo de Maynas, José María de Arriaga, en 1842 advertía al gobierno que no estaba resultando el envío de gobernadores a determinados pueblos conversos, en tanto que aquellos habían sido enviados más bien por la escasez de sacerdotes con la finalidad de que enseñen la doctrina cristiana a los neófitos, cosa que no se había logrado «pues ni persignarse saben»; además, afirmaba, estos gobernadores hacían fortuna con los repartos, las mitas y los impuestos. El obispo Arriaga sentenciaba que aquellos pueblos -se refería en concreto a tres: Sarayacu, Yurimaguas y San Regis- no necesitaban más gobierno que los eclesiásticos, sus curacas y justicias; en otras palabras, los gobernadores por parte del estado eran innecesarios en esos puntos ${ }^{17}$. El cambio del sistema político en el Perú no modificó la situación en Maynas.

15 Hipólito SÁNCHEZ RANGEL, Pastoral religioso-política, geográfica, p. 1.

16 Ibid., pp. 157-158.

17 «De la visita del señor obispo en Pebas», 1842. Carlos LARRABURE y CORREA, op. cit., tomo XI, p. 114. 


\section{NO HAY CLERO QUE SE DÉ ABASTO}

Según el obispo Hipólito Sánchez Rangel, el obispado de Maynas estaba conformado por cinco parroquias. Archidona, Santa Rosa, Ávila, Lamas y Moyobamba, servidas por curas interinos pagados por los tributos de los indios. «Las demás iglesias del Obispado todas son misiones, doctrinas o reducciones de puros indios y algún blanco o mestizo». El problema mayor, precisamente, era este conjunto de misiones o reducciones indígenas, donde el clero no llegaba, y si lo hacía, era inconmensurable su labor. Sánchez Rangel graficaba esta situación con expresiones muy significativas. Sobre dos doctrinas del río Napo decía:

Cuando yo estuve allí no se hallaron en estos puntos más que una casa o tambo de paja, un perro y algunas gallinas. Para estos países y los intermedios del $\mathrm{Pu}-$ tumayo, Yapurá, Napo... con otros infinitos de la diócesis, se necesitaban un San Francisco Javier o un San Francisco Solano, que no los hay ahora, muchos pesos y muchos años ${ }^{18}$.

En 1815 el obispo decía que se necesitaban diez sacerdotes para completar los «huecos» que había en toda la diócesis. Poco después, en 1822 cuando se encontraba fuera del Perú, en un informe dirigido al Papa en que le detallaba el estado de la diócesis, mencionaba que el número de sacerdotes que él había dejado en el obispado era nada más que de veinticinco a treinta contando con los de Ucayali (más al sur, zona a la que le llama «misiones vivas de infieles»). No obstante, para que el Obispado estuviera bien servido y progresaran las misiones, él calculaba que eran de absoluta necesidad cien sacerdotes en Maynas más doce o quince en la capital-Moyobamba- para remudar a los misioneros ${ }^{19}$.

Definitivamente, este era uno de los grandes problemas de Maynas y era un tema recurrente en muchos de los documentos que el obispo elaboró. Así, desde España en 1827, haciendo alusión a la visita de la década de 1810, Sánchez Rangel decía: «Un solo cura o doctrinero, o algún otro que se manda de cuando en cuando es el que provee de lo espiritual todas estas tierras. ¿Qué Obispo no se afligirá con esto? Tanto más porque acaso, inclusas las misiones de Manoa, no llegan a cincuenta sacerdotes todos los del Obispado» ${ }^{20}$. Para la enorme extensión territorial, calculada en «seis mil leguas cuadradas en su circunferencia ${ }^{21}$, finalmente

\footnotetext{
18 Ibid., tomo VIII, p. 336.

19 Ibid., p. 259.

20 Hipólito SÁNCHEZ RANGEL, Pastoral religioso-política, geográfica, p. 151.

21 Ibid., p. 4.
} 


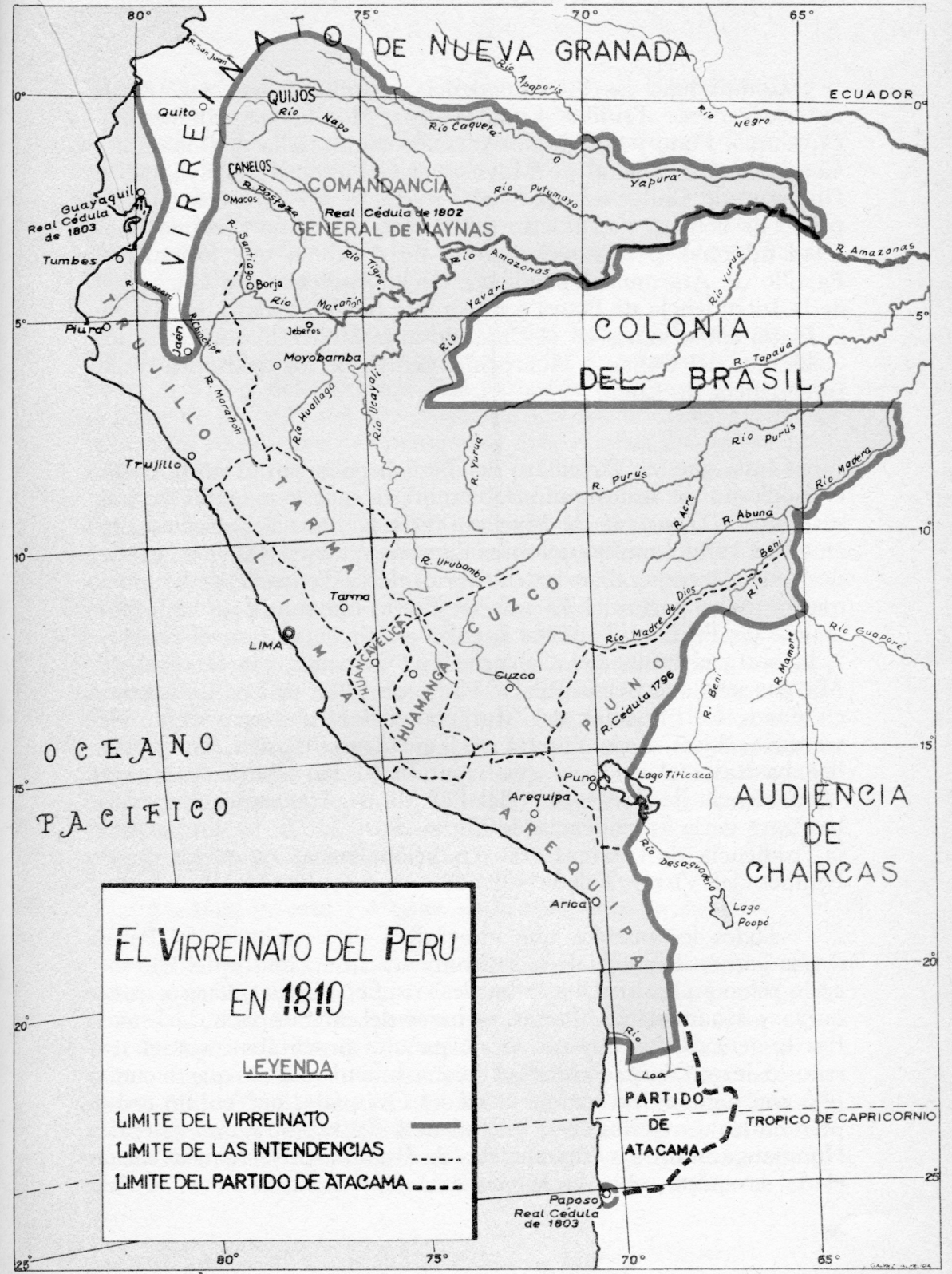

Mapa 2. «El virreinato del Perú en 1810».

Fuente: Gustavo Pons Muzzo, Las fronteras del Perú (Historia de los límites), Lima, Iberia, 1961, p. 47. 
Sánchez Rangel incrementó el número de curas que consideraba imprescindibles para Maynas: «Eran necesarios si se hubiera de servir toda, y entablar misiones en todos los puntos que comprende, cuando menos quinientos sacerdotes en actual ejercicio y otros tantos para reemplazarlos» ${ }^{22}$.

Antes de conformarse Maynas como obispado, parte de las misiones de ese espacio estaban atendidas por los frailes franciscanos del convento de Ocopa, como mencionábamos. Pero Sánchez Rangel, franciscano también, tuvo muchos problemas con ellos, los que trascendieron al ámbito político, teniendo que intervenir el virrey Fernando de Abascal en el tema. Según la interpretación que el obispo hizo de la real cédula de creación del obispado de Maynas, además de dos canónigos asistentes, contaría con el apoyo de los padres franciscanos hasta que hubiese clero. Esto supondría de alguna manera la sujeción de los franciscanos de Ocopa a determinadas directrices del prelado. Pero, y a pesar de que el obispo justificaba que llevaba razón en lo que les solicitaba para la atención de algunas doctrinas de la diócesis, los frailes hicieron caso omiso abandonando muchas reducciones ${ }^{23}$. No es la intención detallar los enfrentamientos entre los franciscanos y el obispo, sino mencionarlo como un problema añadido que se evidenció en la visita y en el gobierno del obispado. Como los padres de Ocopa no habían querido acudir a su llamado, Sánchez Rangel tuvo que asistir las iglesias destinando personas no idóneas, dificultándose con ello la continuidad de la evangelización. En el informe al Papa (1822), mencionaba que por esta negativa o imposibilidad de los frailes de Ocopa, había tenido que «... ordenar a muchos que no se lo merecían para llenar los principales huecos» ${ }^{24}$. De hecho, afirma que dichos eclesiásticos $\ll . .$. son nada más que para aquellas tierras... Saben lo muy necesario para la administración de los sacramentos y la enseñanza de la doctrina. El actual gobernador interino de la mitra es un simple sacerdote, bastante escaso, pero sobresale a los demás en su buena conducta, fidelidad, mucha caridad, está instruido por mí...» $\gg^{25}$. Como se ve, no se pudieron colmar eficientemente los espacios que necesitaban sacerdote.

Esta carencia fue un problema que llegó a la república. En 1833 el gobernador eclesiástico del obispado de Chachapoyas, decía que faltaban sacerdotes

22 Ibid., p. 131.

23 Otro ángulo del conflicto entre los franciscanos de Ocopa, el estado colonial y el obispo de Maynas, en Rubén VARGAS UGARTE, El episcopado en los tiempos de la emancipación sudamericana, Lima, Librería e Imprenta Gil, 1962, pp. 148-149.

24 «Informe dirigido a su santidad por el obispo de Mainas acerca del estado de su diócesis, 1822». Carlos LARRABURE Y CORREA, op. cit., tomo VIII, p.259.

25 La cursiva es nuestra. Ibid., p. 260. 
en las misiones, pues los pueblos estaban $\ll . .$. en el mayor riesgo de volver a su antigua creencia...». Envió por ello un pedido a todas las parroquias y conventos de Lima solicitando sacerdotes voluntarios. Todos le contestaron negativamente, o por salud de los presbíteros y religiosos, o por edad, o porque no había a quién enviar $^{26}$. Si no hay clero que se dé abasto, ya sea por la falta de buenos curas, por las distancias y dificultades del terreno, o por los conflictos surgidos entre clero secular y regular, lo cierto es que se percibe, como afirma García Jordán, la impotencia de la Corona y del aparato colonial para implementar una política en el Oriente peruano ${ }^{27}$. Termino este punto con una afirmación del obispo que me parece resume su desazón y nulo control de su espacio: «A la verdad, sin clero secular ni regular y sin arbitrios para formarlo, es un delirio llamarle a esto Obispado» ${ }^{28}$.

\section{LOS INDIOS EN MAYNAS, SITUACIONES DE CONFLICTO}

Para 1814, según datos del censo remitido por el obispo, la población total de Maynas era de escasamente 25.641 almas $^{29}$. La población indígena en concreto en este obispado, como decíamos antes, tenía diverso grado de civilización. Se habla de misiones de infieles, gentiles, antropófagos, salvajes liderados por curacas o reyezuelos y también indios cristianizados no convencidos totalmente de su nueva fe. En muchos lugares el sacerdote tenía que ganar la atención de los indios con algunos instrumentos de mucha o poca utilidad, como lo afirma José Julián del Castillo para las misiones del Ucayali: «Para estas Misiones se necesitan lo menos diez sacerdotes... con una remesa de 500 pesos anuales empleados en agujas, anzuelos, tijeras, espejos, cuchillos, hachas, machetes o rozones para congratular y atraer a la religión a los infieles bravos según se acostumbraba en el gobierno español... ${ }^{30}$. Esta realidad convertía en inasibles a los indios, en peligrosos y temidos inclusive en aquellos pueblos donde el clero había podido de alguna manera asentarse.

26 AAL. Serie: Documentos de Jaén, Maynas y Chachapoyas, leg. 1, exp. 39, años 1832-1833.

27 Pilar GARCÍA JoRDÁN, Cruz y arado, fusiles y discursos, p. 53.

28 AAL. Convento de San Francisco, leg. 11, exp. 30, año 1819, p. 3v.

29 Ricardo García Rosell, Conquista de la Montaña. Sinopsis de los descubrimientos, expediciones, estudios y trabajos llevados a cabo en el Perú para el aprovechamiento y cultura de sus Montañas, Lima, Tip. «La Prensa», 1905, s.p.

30 AAL. Serie Curatos. Amazonas, leg. 36, exp. 11, año 1828, fol. 2 v. 
En la visita eclesiástica, el obispo mencionaba que había bautizado, confirmado y casado a cientos de indígenas de pueblos recónditos. Pero como se sabe los indios bautizados no estaban necesariamente convertidos; era común que ni siquiera entendiesen la gravedad de lo que se estaba tratando, como se desprende de las afirmaciones del prelado: «Al paso y en la visita general... bauticé, confirmé y casé a infinitos gentiles. ¡Qué docilidad! ¡Qué candor! ¡Qué inocencia! Pero en cueros hombres y mujeres, mirando y riéndose de todo». Y de otro encuentro dice: «... bauticé, confirmé y casé a muchos quedándose estáticos en ver la ceremonia. Uno me agarraba el pectoral, y mirándome se reía con una santa simplicidad. Cual me daba una fruta o pescado, y cual estaba como admirándose sin saber qué hacerse, ya se sienta, ya se levanta... ¡Qué candor y qué sencillez! Pero no pude reducirlos a que se taparan sus carnes, por más que se les dieron camisas y calzones ${ }^{31}$.

Dentro de este conjunto poblacional, grosso modo, había pueblos de indios que querían ser cristianizados, pero también existieron otros en los que era más difícil conseguir siquiera que se establecieran de manera definitiva, o que no se rebelaran. Se le informaba al obispo Sánchez Rangel:

He notado el carácter pésimo de los indios de Archidona y especialmente de los de Loreto que huyen y son naturalmente enemigos de vivir en sus poblaciones y de concurrir a las precisas obligaciones de cristianos, habiéndoseles notado a los de Loreto la insubordinación a sus curas, pues al presbítero D. Bernardo Bedoya se le amotinaron algunos y me aseguraron lo habían estropeado, y que también le pegaron fuego a la casa conventual... ${ }^{32}$

Los indios se desplazaban con o sin consentimiento de la autoridad, fundaban otros pueblos, escapaban del control, de los tributos, de los aranceles eclesiásticos, de los servicios personales, o se acercaban más a lugares donde podían comerciar a sus anchas. En la visita pastoral a la región del Putumayo en 1808, los indígenas del pueblo San Miguel del Río, Piscoyacu y Saposoa elevaron una solicitud. Decían que hacía más de 20 años (1788 aproximadamente), más de la mitad del vecindario había tomado la decisión de irse de esos lugares hacia una región de Lamas por razones diversas: más espacio, buenas tierras para labranza y ganado, y por estar cerca a otros pueblos con conexiones más fáciles hacia Trujillo y Lima. Argumentaban que el anterior obispo de Trujillo, Baltasar Martínez

31 Hipólito SÁNCHEZ Rangel, Pastoral religioso-política, geográfica, p. 188.

32 ARCHIVO ARZOBISPAL DE CHACHAPOYAS (AACh). Serie: Visitas pastorales, leg. 5, años 18081810. 
Compañón, había dispuesto en su visita que la ciudad debía traspasarse a otro lugar. Pedían ahora licencia al obispo de Maynas para poder irse todo el vecindario. Ya habían conseguido que el cura aceptase traspasarse también. Paralelamente, decían, tenían un recurso iniciado en la audiencia de Lima. No obstante todo lo argumentado por los indios, Sánchez Rangel no aceptó el traslado y ordenó la suspensión de fábricas de iglesias, prisión a los indios revoltosos y que los otros temas pasaran al comandante general de Maynas.

¿Por qué el obispo fue en contra de un establecimiento que llevaba más de dos décadas? Porque, afirmaba, los documentos de los indios eran falsos. En 1798 pasó por el lugar un juez eclesiástico comisionado que les dijo que no había permiso para sus pretensiones. Pero no reconocieron su autoridad. Por otro lado, no estaban tan cerca de poblaciones más civilizadas como decían, sino más lejos, selva adentro. La intención de los indios -y de los vecinos españoles que estaban con ellos- era introducir contrabando de tabaco sin ser fiscalizados. Finalmente, decía el obispo, los indios se han ido a otro lugar «por no atender a los señores jueces y a los curas». El expediente llega hasta aquí. No se les da permiso para trasladarse y antes bien el obispo determina que regresen a su establecimiento original, cosa que no sabemos si llegó a suceder. El obispo decía que los indios «quisieron engañar así como lo practican siempre» ${ }^{33}$.

No sabemos cómo se manejaban los jueces eclesiásticos y curas que servían estos pueblos, ni por qué razones concretas los indios se querían alejar de ellos. Pero hay que introducir otro elemento de análisis. En la carta que el ex gobernador de Maynas y comandante de la Expedición de Límites al Marañón, Francisco Requena, escribió al padre guardián del convento de Ocopa, manifestaba: «Así los jueces en Maynas, como los Misioneros, ejercen sobre estos Naturales la respectiva jurisdicción debida a los fueros Real y Eclesiástico; y desde luego por pequeñas faltas los condenan a un número de azotes proporcionado al delito ${ }^{34}$. Requena califica de «... abominable esta fatal costumbre que no es privativa de solo Maynas». Como es lógico, no estamos ante una única interpretación del suceso.

$\mathrm{El}$ anterior es un caso de cómo los indígenas intentan manejar sus espacios y a las propias autoridades, pues mientras le pedían permiso al obispo en la visita que hacía a esta región para quedarse en el nuevo lugar, ya habían conferido poder a un fiscal para que a nombre del común de indios elevase la solicitud al

33 AACh. Serie: Visitas pastorales, leg. 5, años 1808-1810.

34 Carta del señor Don Francisco Requena, gobernador de los Maynas, al R.P. Guardián de Ocopa con algunas reflexiones referentes al mejor gobierno y progresos de las Misiones del Ucayali, en Mercurio Peruano, edición facsimilar, tomo IX, 1793, fol. 2. 
superior gobierno. Pero no siempre lo hacían por engañar al clero, sino porque efectivamente tenían problemas.

El cura del pueblo de Loreto, en 1808 y durante la visita, escribió al obispo acerca del pedido de los «infieles» de fundar otro pueblo por las plagas que había y por los maltratos de los soldados. Aquí hay otro asunto que se escapa de las manos de las autoridades. El cura de Loreto se quejaba de que los blancos de la frontera usaban a los indios en mingas y servicios personales impidiéndoles asistir a misa los días de fiesta; entre esos blancos estaban los soldados de la Expedición de Límites del Marañón, financiada por España y Portugal. Los indios referían estar cansados de servir a esta Expedición, inclusive se hablaba de «indios de expedición» como una categoría más en algunas zonas. Respecto al accionar de esta expedición, José María Padilla, secretario del obispo, informa que una de las razones por las que no conviene quedarse en Jeberos, primera capital del obispado, es porque se trata de una zona «miserabilísima, sin recursos ninguno, y cuando hay alguna providencia [cuando cede la creciente del río Marañón] todo se acopia por la partida de Expedición a todo costo y de cuenta del Rey...» ${ }^{35}$.

La fundación de nuevos pueblos de indios puede tener variedad de causales. Las situaciones son complejas porque tienen que ver con zonas de una frontera que se está midiendo, estudiando, vigilando, con todos los efectos negativos que eso puede suponer; son zonas distantes de las autoridades locales y más aún del gobierno central virreinal. El propio obispo mencionaba como problema que los indios se hallaban errantes entre las fronteras española y portuguesa ${ }^{36}$. Si bien la visita podía servir en muchos casos para administrar justicia o mediar en conflictos políticos en zonas como Maynas, nunca fue suficiente.

Sánchez Rangel encontró en Quijos un gobernador «bien perverso». En vista de las quejas de los indios, dio cuenta al virrey Abascal, pero siendo tan larga la distancia a Lima y tardando la superior disposición, los mismos indios hicieron justicia. Aunque el gobernador se escondió entre las ropas de la imagen de la Virgen, lo sacaron de allí, lo maltrataron y dejaron casi muerto. Luego es que llegó la orden del virrey de sacar al gobernador de ese puesto. Es, pues, uno de los muchos casos que pudieron darse en los que el estado no llegó y la intervención del obispo no pudo detener las acciones de la comunidad. En determinadas situaciones, con los indios había que irse con cuidado, había que ser conciliador.

35 AACh. Serie Visitas Pastorales, leg. 5, años 1808-1810.

36 Carlos Larrabure y CORREa, op. cit., tomo VIII, p. 333. 
En 1819, el gobernador político de la provincia de Quijos, Rudecindo del Castillo Rengijo, había determinado que los indios de dos provincias -Concepción y Cotapino- pagasen el derecho de única contribución en oro y no en pita (producto que servía para hacer sogas) como siempre lo habían hecho. Esto significaba que los indios tenían que desplazarse a los lavaderos de oro ubicados en lugares inaccesibles, donde peligraban sus vidas, sus bienes y las chacras que abandonaban por irse a conseguir el mineral. ¿A quién acudieron los indios en esta ocasión? Recurrieron al poder eclesiástico y al poder civil en paralelo, es decir, a su cura párroco, Francisco Ibáñez y Campo que era además juez eclesiástico, y también enviaron informes al teniente general de Quijos, Antonio Lemus, y al teniente de los pueblos de Ávila, Loreto y Payamino, Manuel Rengijo, sobrino del acusado gobernador Rudecindo del Castillo. Es Ibáñez y Campo, párroco y juez eclesiástico, quien por oficio acusó al gobernador de la provincia. Ambos terminaron diciéndose cosas muy fuertes. En este caso, el cura Ibáñez se puso del lado de los indios porque las razones que estos le dieron -antes señaladas- las consideró valederas. Inclusive, sofocó un intento de rebelión de los indios, condescendiendo:

Ayer se me presentó todo el pueblo de la Concepción y el de Cotapino, a quienes, después de hacerles ver la obligación que tenemos todos los vasallos del Rey, a aliviarlo y a sacrificarle vidas y haciendas... les ponderé el perjuicio que recibía la Majestad Católica con su única contribución en pitas... Después les hice presentes las urgencias en que se hallaba el Rey por la revolución de los lugares... y que... procuren solicitar lavaderos de oro... Me han pedido tres semanas de término... porque si no encontrasen dichos lavaderos seguirían pagando en pita. He convenido en ello ${ }^{37}$.

En otras palabras, Ibáñez tiene que negociar, ceder frente, como él mismo dice, a todo el pueblo. José María Padilla, secretario del obispo de Maynas, derivó el caso al virrey del Perú, Joaquín de la Pezuela. Las acusaciones iban y venían entre las autoridades implicadas. Pero lo que realmente les preocupaba era la respuesta final de los indios. Por un lado, estos expresaron que «aunque los maten no pagarán este tercio en oro por no haberlo en sus playas». Pero también había un gran temor a otro tipo de acciones. Ibáñez pedía se solucione el conflicto «y Dios quiera sea antes que nos quiten los indios las vidas» ${ }^{38}$. ¿Era una alarma innecesaria? En realidad no, pues varios testigos dieron noticia de que, en un pueblo

37 La cursiva es mía. AACh. Serie: Visitas pastorales, leg. 5, años 1808-1810.

38 Ibidem. 
cercano, los indígenas habían incendiado la casa del párroco en desacuerdo por los gravámenes que este les solicitaba.

Respecto al comportamiento de los naturales, estos actúan en todo momento de diferentes maneras: yendo a casa del cura y juez eclesiástico para hacerle saber sus angustias y ponerle límite al asunto que estaban viviendo; huyendo; ejerciendo la violencia contra quienes les oprimían; y junto con lo anterior, notificando a la autoridad civil-militar del lugar sobre los excesos. Este caso no empieza siendo un tema eclesiástico, ya que se trata del pago del ramo de única contribución que, al no poderse hacer en especie, atentaba contra una tradición a la que ya se habían acostumbrado los indios; pero termina convirtiéndose en una cuestión sancionada por las autoridades eclesiásticas debido a las informaciones paralelas que fueron surgiendo y engrosando el expediente. Los indios ejercían una gran presión.

En 1811, José María Padilla se hizo eco de las «muy repetidas quejas» que tuvo «sobre el excesivo y tiránico trabajo que lamentaban los indios de esta ciudad... de unos amos indolentes, sin caridad y sin compasión...». Ya a fines del siglo XVIII, el gobernador de Maynas, Francisco Requena, llamó la atención en concreto sobre los excesos de los misioneros en el servicio personal que exigían a los indios: «... les traen la sal de las minas que hay en la Misión, les hacen la manteca de las charapas, les salan pescado, y los emplean en fuerza del dominio que ejercen en ellos, por un abuso mal introducido, en cuantas diligencias quieren ocuparlos de su peculiar lucro...» ${ }^{39}$. El fiscal del reino (23/06/1811) y luego el virrey Abascal, por decreto del 5 de agosto de 1811, determinaron se eliminasen los servicios personales en la diócesis de Moyobamba. Se estableció que los indios no podían servir a otro sin autoridad del protector de naturales, y que no habiendo Protector esta función la podría cumplir el cura. La decisión del virrey es anterior al decreto de Cortes (09/11/1812) que suspende este mismo asunto para los indios de los reinos de ultramar ${ }^{40}$. Podríamos considerarlo como un triunfo más de los indígenas en esa relación con las autoridades de las que podían obtener justicia.

Si bien hemos descrito situaciones que se suscitaban por el accionar de pueblos de indios más o menos organizados, que podían manejarse en distintos ni-

39 «Descripción de los varios caminos que dan paso desde la ciudad de Quito al río del Marañón para acompañar al mapa que de ello se ha formado...» de Francisco Requena, 1785, en Boletín de la Sociedad Geográfica de Lima, tomo LXII, 1945, p. 116.

40 Aunque no sea el tema, es importante mencionar que ejemplos como este ratifican la mirada historiográfica que incide en que no todas las propuestas de este tipo empezaron en Cádiz; ya en los propios reinos americanos se venían haciendo nuevas propuestas. 
veles en sus solicitudes o actuaciones, la realidad es que el conjunto poblacional que abundaba en la selva amazónica, según las distintas autoridades, era el de los grupos humanos que no se hallaban del todo establecidos, los que podríamos identificar como los llamados salvajes y los considerados antropófagos que se mencionaban al inicio de este epígrafe. Era este el prototipo de habitante que representaba a todo el obispado o a toda la región. Ese imaginario venía de la mano de una catalogación peyorativa que perduró prácticamente todo el siglo XIX. Así tenemos, por ejemplo, al subprefecto de Maynas, Carlos del Castillo Rengifo, quien en el plan topográfico que realizó de esta gobernación en 1834, habla de «habitantes reducidos en sociedad»y de «cantidad de autómatas que habitan los bosques de este vasto océano de montaña...». En otra parte del documento, del Castillo se expresaba de ellos como este «pequeño número de semiracionales». Luego de describir las grandes producciones de materias primas de este espacio, sentencia que por el momento el gobierno no debía contar con estas riquezas, sino con «el desembolso de grandes sumas para contener a los indígenas, y muy particularmente a los neófitos que detestan la sociedad, quienes emigran diariamente a lugares desconocidos por falta de azote... $\gg^{41}$. Se trata de una mirada generalizada entre las autoridades en el siglo XIX republicano.

En muchos casos, la educación y catequesis tampoco daban resultado. Era muy difícil que los pobladores aceptasen el adoctrinamiento y las primeras letras en la escuela. Los informes (1843) hablan del «... ningún aprecio que hacen los padres de familia de esta clase de educación, pues... los remontan o no sé dónde los meten cuando los ven destinarse para adoctrinarlos, y solo el temor del castigo que se les aplica, hace que tengamos actualmente seis niños, que se hallan deletreando, al paso que son poco a poco instruidos en el castellano, habiendo fugado dos de los primeros, que fueron los mejores» ${ }^{42}$. El segundo obispo de Maynas, José María de Arriaga, estableció una escuela gratuita de primeras letras en el Seminario de Moyobamba (1843), según sus palabras, «para el bien de la Iglesia y del Estado» ${ }^{43}$. Evidencia de que ese cometido interesaba al gobierno civil de la provincia, es el hecho de que el obispo recibe el apoyo del subprefecto e intendente de policía de Maynas, quien ordena que todos los padres de familia

41 La cursiva es mía. «Plan topográfico de la provincia de Mainas por su subprefecto don Carlos del Castillo Rengifo. Moyobamba, septiembre 4 de 1834» en Carlos LARRABURE Y CORREA, op. cit., tomo XIV, p. 266.

42 José Inocencio Hidalgo al obispo José María de Arriaga. Jeberos, 19 de junio de 1843 (Carlos LARRABURE Y CORREA, op. cit., tomo IX, pp. 453-454).

43 Moyobamba, 27 de septiembre de 1843. Ibid., pp. 455-456. 
quedaban forzosamente obligados «bajo la más estricta responsabilidad, a poner a sus hijos en la escuela pública que se va a establecer, bajo la dirección del ilustrísimo señor obispo... ${ }^{44}$.

Finalmente, las dificultades con la población de Maynas venían también por el lado de las distintas lenguas que hablaban los grupos que poblaban la Amazonía: «Mas este pequeño concurso representaba un Babel, porque el castellano, el inca, el portugués, el brasilero, el ticuna, el cunivo eran los idiomas de sus individuos». Si esta variedad de lenguas no suponía un reto de por sí, podemos imaginarnos la frustración de no contar con intérpretes que pudieran transmitir las verdades de la fe:

En medio de esta dificultad, restaba saber si los intérpretes trasladaban rectamente nuestros períodos [sic], porque uno de ellos había hecho esta traducción: «Jesucristo está en Loreto» en lugar de esta otra «Dios está en todas partes». Aún aquellos indígenas al parecer instruidos estaban envueltos en semejante ignorancia. Así, preguntado uno de ellos «Volverá Jesucristo a la tierra?» Sí, respondió frescamente «volverá conduciendo zarza para negociar en Tabatinga». Otro contestó: «Dios se ha quedado en la vuelta del río» ${ }^{45}$.

Como vemos, veinte años después de las guerras de independencia y de la salida del obispo Sánchez Rangel, en la selva peruana se suscitaban los problemas de siempre y se daban las mismas dificultades de inicios de la evangelización en las regiones de la costa y de la sierra. En Maynas parecía que la catequesis estaba siempre comenzando.

\section{PROPUESTAS DEL OBISPO PARA EL CONTROL DEL OBISPADO}

Durante el tiempo en el que Hipólito Sánchez Rangel estuvo a la cabeza del obispado de Maynas, solicitó en reiteradas ocasiones el cambio a otro destino argumentando no estar en condiciones de salud para permanecer ahí. Se prometió acceder a su pedido por real orden de 1814, pero no se hizo efectivo. De 1819 data la última solicitud que interpuso el obispo para su cambio o retorno al convento franciscano ${ }^{46}$. Estas peticiones no hacen sino evidenciar, además de las enfermedades que con seguridad sufrió el obispo, el cansancio en la labor

44 Moyobamba, 30 de setiembre de 1843. Carlos Larrabure y CORREa, op. cit., tomo IX, p. 459.

45 Viaje a los ríos Pachitea y Pozuzo por los PP. Fr. Manuel Plaza y Fr. Juan Crisóstomo Cimini. 1841. Carlos LaRrabure y CORREA, op. cit., tomo XI, p. 106.

46 AAL. Jaén, Maynas. Chachapoyas, leg. 1, exp. 9, año 1819, fol. 1-1v. 
evangelizadora en un espacio de tamañas dificultades. En otros informes nos dice que llegó a su destino en Perú sin tener conocimiento de las características de la diócesis que iba a gobernar. En efecto, por muchas referencias que se pudiesen tener, las expectativas chocaban con la realidad una vez llegados allí. Andando el tiempo, sabiendo de los pocos recursos humanos con que se contaba para el obispado, el desánimo se hacía evidente.

Se han podido advertir en estas páginas las grandes dificultades que una zona de misión en la selva amazónica tenía para cualquiera. Considerando esto, así como la propia experiencia en el lugar, el obispo hizo algunas propuestas de reforma para el mejor gobierno y control del obispado. Él afirmaba que tenía en mente una gran reforma, la que fue elevada a Madrid muchas veces. Hasta el momento hemos encontrado tres propuestas.

Al terminar la visita, Hipólito Sánchez Rangel remitió al Consejo de Indias un proyecto para la mejora y felicidad de la provincia de Maynas, enviada a España alrededor del año 1814. No tenemos el Proyecto pero sí la respuesta del virrey Abascal. En esta primera propuesta, el obispo pedía para Maynas seis puntos: si convenía suprimir el gobierno militar de esa provincia; los recursos que había que tomar para el envío de familias industriosas a esa diócesis; la apertura de un camino que conectase con la capital; abrir en dicho camino comunicación con el río Marañón; impedir, siguiendo el punto anterior, la invasión y contrabando de los portugueses; y finalmente, impedir los riesgos que podrían sobrevenir o suscitarse con Portugal. En este proyecto se hacen evidentes esas funciones que, se asumían, también debían cumplir los misioneros sobre todo en la selva: exploración del territorio, apertura o mejora de rutas de penetración en la Amazonía ${ }^{47}$, o como se exponía en anteriores párrafos, opiniones sobre cómo administrar mejor un espacio. Ello explica que el obispo propusiera temas de tanta radicalidad y que tenían más que ver con actividades políticas que espirituales. Para dar respuesta, el gobierno se sirvió a su vez de otros miembros del clero.

El virrey Abascal, siguiendo el consejo de dos frailes franciscanos, Luis Colomer y Narciso Girbal ${ }^{48}$, que habían servido en las misiones de la selva, dio

47 Pilar García JoRdán, Cruz y arados, fusiles y discursos, p. 26.

48 Narciso Girbal, franciscano del convento de Ocopa, se dedicó a recorrer la selva, debiéndosele a él los primeros artículos sobre esta región. Girbal fue muy un misionero que contaba con muy buena opinión entre las autoridades, como por ejemplo el gobernador de Maynas, el conocido Francisco Requena. Algunas notas de sus viajes al interior del Perú: «Peregrinación por los ríos Marañón y Ucayali a los pueblos de Manoa, hecha por el padre predicador apostólico fray Narciso Girbal y Barceló en el año pasado de 1790», en Mercurio Peruano, tomo III, edición facsimilar, 1791, fols. 49-72. «Segunda peregrinación del padre predicador apostólico fray Narciso Girbal y Barceló, 
respuesta negativa a todos los puntos aunque con algunas acotaciones importantes. Respecto a lo primero, los frailes veían de absoluta necesidad el gobierno militar de Maynas por ser frontera con Portugal ${ }^{49}$; no obstante, sí consideraban digna de supresión la partida de la Expedición de Límites «contra la cual han clamado justamente los indios». Esto nos hace deducir que en el Proyecto elaborado por Sánchez Rangel también se hacía alusión a esta Expedición, pues había sido muy injusta con los indígenas del lugar sobre todo en cuanto a los servicios personales. Los indios huían de los «blancos» de la Expedición. Por otro lado, Colomer y Girbal consideraban impracticable enviar familias industriosas desde otros puntos a Maynas, «por la diversidad del clima que las haría... perecer», y porque se sentirían desterradas y en tierras «incómodas». Si no eras del lugar, la selva amazónica no constituía una opción a considerar para hacerse de tierras o empezar algún tipo de industria; inclusive tampoco los lugareños se afincaban, eran poblaciones que se movían mucho, como hemos anotado. Tal es así que en la república el gobierno brindó alicientes para que se quedaran en el lugar o para que los extranjeros se avecindaran en Maynas ${ }^{50}$.

Acerca de abrir un camino que vaya a la capital, Abascal afirma que los religiosos «... [lo] tienen por el mayor de los imposibles por lo cubierto y encadenado que se halla aquel país de cerros inmensos y peñascos interminables, y de no traer utilidad alguna la transportación de géneros aún en el caso de ser practicable $»^{51}$. Esta afirmación choca con el conocimiento que desde hacía décadas se tenía de la riqueza en productos naturales de la selva. Ya en 1791, fray Manuel Sobreviela había publicado en el Mercurio Peruano una extensa relación de la producción de Maynas, referencia a la que alude uno de los visitadores en la zona del Huallaga a

a los pueblos de Manoa», y «Noticias interesantes a la religión y al estado escritas desde Manoa con fecha 3 de abril de 1792, por los padres misioneros de Ocopa fray Narciso Girbal y Barceló y fray Buenaventura Marques...», en ID., tomo V, 1792, edición facsimilar, fols. 89-113 y fols. 116-123.

49 Este era un problema no solo de defensa de los límites territoriales, sino en relación con los indígenas. Para 1834, el subprefecto de Maynas, Carlos del Castillo, mencionaba, entre otros problemas: «El abandono de estas fronteras hace poner en práctica a los brasileros el infame uso de la violencia que no pueden resistir nuestros infelices salvajes que la padecen en la línea divisoria de ambas naciones... los raptores triunfan a beneficio del estruendo del cañón que lleva la desolación y la muerte en el río Putumayo» (Carlos LaRRabURE y CORREA, op. cit., tomo XIV, p. 267).

$50 \ll$ Se ordena al subprefecto de Maynas preste protección a los salvajes orejones que tratan de establecerse a orillas del río Ambiyacu, 1832», «Erección de un colegio de propaganda fide en Jeberos y concesión de tierras a los extranjeros que se avecinen en Maynas, 1832», «Concesión de terrenos en la región del Pastaza al curaca don Bernardo Muranama, 1836», «Se concede a los que cultiven terrenos en las reducciones del Ucayali la propiedad de ellos, 1845», entre otros dictámenes. Carlos LARRABURE Y CORREA, op. cit., tomo V, p. 8-10, 16.

51 AGI. Lima, 1017. Años 1814-1815, fol. 1v-2. 
fines de la década de 1790. El obispo Sánchez Rangel también tenía un amplio conocimiento sobre la producción económica de Maynas, la que puso por escrito en su Pastoral (1827) con gran detalle. Volviendo al proyecto, sobre los demás puntos, la negativa también es rotunda, concluyendo el virrey el informe con la siguiente idea: «el único medio de mejorar la suerte de aquellos habitantes es la buena elección de los que los gobiernan tanto en lo político como en lo espiritual $\gg^{52}$. Al parecer, el consejo de Indias tomó en cuenta la opinión del virrey Abascal, puesto que no hubo ningún cambio en la diócesis que tuviese que ver con los pedidos del obispo para, como rezaba el título, la felicidad de aquella provincia.

El prelado fue muy crítico con quienes consideraba responsables de que las cosas no funcionaran en Maynas. Sánchez Rangel le escribió a Bartolomé de las Heras, arzobispo de Lima (1820): «Yo no puedo con esto absolutamente, y si no se toma una medida juiciosa que pueda darme algún alivio, seré víctima...». El obispo acusaba al ex gobernador de Maynas, Francisco Requena, y a los franciscanos del convento de Ocopa de que, buscando posicionarse -sobre todo el primero-, habían tenido que ver en la creación del obispado de Maynas. Era por todos sabido que los informes -y mapas- que Francisco Requena remitió a la corona sobre la pertinencia de segregar algunos territorios del obispado de Santa Fe e incorporarlos a un nuevo obispado en la selva norte del Perú que incluyese también las misiones de Maynas, en abandono luego de la expulsión de los jesuitas, tuvieron mucho que ver en la decisión de la corona de erigir el obispado de Maynas ${ }^{53}$. Para Sánchez Rangel, Maynas como obispado era un despropósito: «Don Francisco Requena movido, sin duda, por las pretensiones... quiso hacer su mérito inspirando la institución de esta mitra..., pero en unos términos tan vacíos, tan fuera de razón, que solo palpando lo que es esto y lo que ha sucedido pueden conocerse» ${ }^{54}$. No era la primera vez que el obispo afirmaba que se habían equivocado quienes pensaron en Maynas como un obispado que pudiese propiciar un cambio en esas tierras. Pensamos que este es el contexto inmediato de sus siguientes proposiciones.

La segunda propuesta de reforma se incluye en el informe elaborado en 1822 dirigido al sumo pontífice. En él, Hipólito Sánchez Rangel sugiere la agregación de unos territorios al obispado de Maynas y la separación de otros. En el primer caso, proponía, entre varios más, que se agreguen algunos importantes -Caja-

52 Ibid., fol. $2 \mathrm{v}$.

53 Félix Denegri Luna, Perú y Ecuador. Apuntes para la bistoria de una frontera, Lima, Bolsa de Valores de Lima, Instituto Riva-Agüero, Pontificia Universidad Católica del Perú, 1996, pp. 32-35.

54 Carta del obispo de Maynas al arzobispo Las Heras. Moyobamba, 5 de marzo de 1820, en Rubén VARGAS UGARTE, El episcopado en los tiempos de la emancipación sudamericana, p. 398. 
marquilla, Chachapoyas y Chillaos- que formaban parte del obispado de Trujillo. Los puntos a añadirse contaban con «un competente número de curatos» que, con los que había en Maynas, «podían contribuir al seminario del Tridentino para repararlo y criar eclesiásticos naturales de aquellos países...». Esto significaría contar con elemento humano para el servicio eclesiástico y para la sustitución de misioneros. Según el obispo, había autorización para formar un seminario pero no se habían dado las circunstancias. En el caso de la separación de territorios, la finalidad era destinarlos a la jurisdicción de los obispados colindantes -Quito, Cuenca, Popayán- desde los cuales se podrían servir mejor que desde Maynas ${ }^{55}$.

Finalmente, cuando Sánchez Rangel era obispo de Lugo, en su Pastoral religiosa-político geográfica (1827), hace otra propuesta de reforma para toda la diócesis que tenía que ver, como la anterior, con una de sus principales preocupaciones: el control del espacio y la reafirmación de la función del obispo. Afirma que se hacía necesaria la división de Maynas en tres obispados: uno en Quijos, otro en Chachapoyas y otro en la ciudad de Huánuco. Para él era la única manera en que se podía atender tan grande espacio con toda la problemática antes analizada. Pero si esto no era posible, lo que había que hacer era: «... que el obispo que fuere de Maynas no debe residir jamás en la capital, ni tener otra cosa en qué ocuparse que visitar en muchos años hoy un punto, mañana otro, o estando un año en Quijos, al siguiente ir a Maynas, en el otro en Moyobamba y Lamas, etc., y no hay que contar con él para otra cosa de las muchas que son o se atribuyen al Obispado». En otras palabras, que el obispo se dedique a conocer su obispado durante todo su período de gobierno. Se sobreentiende que las demás funciones las delegaría en otros ministros del altar. Es clara la importancia que Sánchez Rangel daba a la visita, hasta el punto de convertir al obispo en un visitador por el resto de su vida. Pero Sánchez Rangel llegó a más en esa misma pastoral: todo el espacio del obispado de Maynas debería contar con entre cuatro a seis obispos, dada la enorme extensión de los pueblos que lo habitan ${ }^{56}$.

55 En este informe, Sánchez Rangel incluye un extenso párrafo describiendo la demarcación del obispado de Maynas. Además, plantea que la silla episcopal, una vez unidos territorios, debería ser Moyobamba o Chachapoyas. «Informe dirigido a su santidad por el obispo de Mainas acerca del estado de su diócesis, 1822» (Carlos LARRABURE Y CORREA, op. cit., tomo VIII, pp. 261-262).

56 Inclusive llegó a afirmar: «Es tan cierta la multitud de indios y mestizos, con algunos españoles europeos y americanos, y tan grande la extensión de los países que habitan y están a mi cargo, que llevando la verdad en mi pluma y el conocimiento exacto de toda o la mayor parte de la diócesis, cuatro o seis obispos con su correspondiente clero, luces y robustez extraordinarias pudieran abastecer de lo necesario todos estos vastos y enmarañados países que la componen» (Hipólito SÁNCHEZ RANGEL, Pastoral religioso-política, geográfica, Imprenta de Pujol, Lugo, 1827, pp. 150-151). 
Hipólito Sánchez Rangel proponía, entonces, una reestructuración muy profunda del obispado de Maynas y del papel del obispo en aquella diócesis: que se dedique únicamente a conocer el obispado, que eso ya le va a llevar todos los años que dure su gobierno. $Y$ es que cuando decíamos antes que el clero no se daba abasto, también nos referíamos al propio obispo, a su figura, a sus humanas fuerzas, situación que está impregnada en varios de los puntos de sus propuestas.

\section{A MANERA DE CONCLUSIÓN Y ALGUNAS REFLEXIONES FINALES}

La visita eclesiástica de Sánchez Rangel advierte grandes problemas en la región: zona de misiones, zona de frontera con Portugal, diócesis inaccesible, con más o menos según el obispo doce tribus distintas de «gentiles», con una geografía y distancias que el gobierno colonial no intentó o no pudo acortar. A pesar de ser en lo político una comandancia general y estar custodiada por tropas y una expedición de límites, ¿qué tan lejano estaba el gobierno de este espacio? No hablamos solo de Lima. Sánchez Rangel escribe su Pastoral sobre Maynas (1827) y la dedica a Fernando VII con estas palabras: «Como Vuestra Majestad tuvo a bien preguntarme dónde estaba Maynas, recogiendo mis pensamientos con algunos apuntes que traía, he compuesto este libro...» $\gg^{57}$.

Esta visita cumplió varias funciones. En primer lugar, la eclesiástica, puesto que el visitador impartía justicia, evangelizaba o catequizaba, advertía la continuidad o no de la prédica y de la imposición de sacramentos, etc. En segundo lugar, la visita tenía una función político-estratégica. El estado no llega a toda la comandancia general de Maynas; el clero se convierte realmente en la selva en la imagen de la autoridad política. Por ello el obispo o sus visitadores se encargaban de describir la geografía, medir las distancias de un punto a otro y demarcar el territorio lo más exacto posible, pues la realidad no coincidía con la plasmada en la real cédula de creación del obispado en 1802. Esta era además una zona de frontera, problemática que se añade a las antes reseñadas. La visita eclesiástica se encargó también de hacer una descripción prolija de las riquezas de la diócesis en todos los órdenes, de las costumbres, del carácter de los indígenas, de las vestimentas o de la falta de ellas, de las plantas medicinales, del comercio interno y externo sobre todo con Brasil, etc. En el medio de todo, la visita manifestaba un gran interés en el control del gran espacio de la selva norte, el que claramente no se podía realizar desde un único

57 La cursiva es nuestra. Ibid., s.p. 
frente y en el gobierno de un solo obispo, por mucho que Hipólito Sánchez Rangel lo intentase, propusiese o ejecutase algunas providencias para ello.

La visita de este obispo no deja acuarelas como sí lo hiciera el conocido Baltasar Jaime Martínez Compañón ${ }^{58}$. Es más, Sánchez Rangel decía en unas líneas de su pastoral que no tenía caudales para levantar e imprimir un mapa; en su defecto, describió las distancias y dibujó una cruz con los puntos cardinales para que sirviera de ubicación de lo que iba a detallar ${ }^{59}$. Aun así, con estas carencias y estando dispersa la documentación, la visita de este primer obispo a Maynas refleja las preocupaciones típicas de los ilustrados. Sánchez Rangel se basa en muchos puntos en la expedición de La Condamine ${ }^{60}$. Es posible afirmar que, como género «visita», la que realiza Sánchez Rangel tiene rasgos que la emparentan más con la documentación expedicionaria, y en ese sentido sigue en importancia a la realizada por Martínez Compañón al obispado de Trujillo, sobre todo por el espacio que abarcó en sus descripciones, y por la vigencia de las apreciaciones y descripciones, más de un siglo después, sobre la selva norte peruana.

La visita se vio limitada por las guerras de independencia en el Perú, con el añadido de la huida del obispo de Maynas a Brasil y luego a la península. Entonces, si ya Maynas era inaccesible, si ya la comunicación era complicada con esta región, es de imaginarse lo que supusieron los años de guerra y los primeros de la república, como se hace evidente de la mano de algunos viajeros extranjeros. El inglés Henry Lister inició una expedición desde Lima hacia el interior del Perú el año 1827. Se comunicó con él Francisco Javier de Echagüe, obispo de Lima, para pedirle, ya que se dirigía a Maynas, le informe a su regreso todo lo relacionado a la situación del obispado (nombres de los curas y capellanes), en tanto que en ese momento «... desconocía totalmente el estado de la diócesis de Maynas, expre-

58 Sobre la importancia de la visita realizada por Baltasar Martínez Compañón a Trujillo del Perú en el último tercio del siglo XVIII, existe una abundante bibliografía. Entre otros títulos: Emily Kay BERQUist, The Science of Empire: Bishop Martinez Compañon and the Enlightenment in Peru, Dissertation presented to the Faculty of the Graduate School of the University of Texas at Austin, Doctor of Philosophy, august 2007; Susan RAmírez HORTON, Al servicio de Dios y de su Majestad. Los orígenes de las escuelas públicas para niños indígenas en el norte del Perú en el siglo XVIII, Lima, Asamblea Nacional de Rectores, 2014. Rubén VARGaS UGARTE, D. Baltasar Zaime Martínez de Compañón, obispo de Trujillo, en Rubén VARGAS UGARTE, Tres figuras señeras del episcopado americano, Lima, Milla Batres, 1966, pp. 165-229.

59 El obispo menciona: «Todos los puntos de que se va a hablar están colocados entre los cuatro cardinales que se ven señalados en la cruz...» (Hipólito SÁNCHEZ RANGEL, Pastoral religioso-política, geográfica, Imprenta de Pujol, Lugo, 1827, p. 156).

60 Ibid., pp. 149, 184. 
sando a la vez su ansiedad de poder controlar los males existentes, pero que hasta que supiera lo que se requería le era imposible actuar» ${ }^{61}$.

Este desconocimiento, que en palabras de Henry Lister afirma tener el arzobispo de Lima, de una zona estratégica como Maynas, en efecto no dista mucho de la situación real de abandono de la diócesis luego del exilio voluntario de su obispo. Aunque este no llegase a conocer toda la diócesis, era el referente para la política local y virreinal, era el que conocía mejor este territorio, era al que el poder central recurría. Ese conocimiento se lo dio la visita de su obispado, pero, además, la vena política que es perceptible en sus pedidos de reforma, en sus luchas contra los franciscanos, en sus propuestas claras de dividir, reagrupar, repartir, adjudicar, eliminar tropas, defender territorio y poblaciones, centralizar, palabras que nos remiten a un proyecto reformador borbónico que buscaba, precisamente, recuperar el control.

\section{REFERENCIAS BIBLIOGRÁFICAS}

\section{Archivos}

Archivo Arzobispal de Lima.

Archivo Arzobispal de Chachapoyas.

Archivo General de Indias.

Archivo General de la Nación.

Biblioteca Nacional de Madrid.

\section{Bibliografía}

BARLETTI, José, La población de Maynas en tiempos de la independencia: análisis de Lagunas y feberos, Documento Técnico n. ${ }^{\circ}$ 9, Instituto de Investigaciones de la Amazonía peruana, Iquitos, 1994.

BELTRÁN RÓZPIDE, Ricardo, Maynas, Publicaciones de la Real Sociedad Geográfica, Madrid, Imprenta del Patronato de Huérfanos de Intendencia e Intervención Militares, 1911.

BERQUIST, Emily Kay, The Science of Empire: Bishop Martinez Compañón and the Enlightenment in Peru, Dissertation presented to the Faculty of the Graduate School of the University of Texas at Austin, Doctor of Philosophy, august 2007.

61 Henry LiSTER MAW, Travesía del Pacífico al Atlántico cruzando los Andes por las provincias septentrionales del Perú en 1827, en Estuardo NúÑ̃z (comp.), Colección Documental de la Independencia del Perú, tomo XXVII, vol. 4, Comisión Nacional del Sesquicentenario de la Independencia, Lima, 1973 , p. 143. 


\section{ELIZABETH HERNÁNDEZ GARCÍA}

Descripción de los varios caminos que dan paso desde la ciudad de Quito al río del Marañón para acompañar al mapa que de ello se ha formado, de Francisco Requena, 1785, en Boletín de la Sociedad Geográfica de Lima, tomo LXII, Lima, 1945.

Denegri LunA, Félix, Perú y Ecuador. Apuntes para la bistoria de una frontera, Lima, Bolsa de Valores de Lima, Instituto Riva-Agüero, Pontificia Universidad Católica del Perú, 1996.

Egutguren Escudero, Luis Antonio, Apuntes sobre la cuestión internacional entre el Perú y Ecuador, vol. 1, Maynas, Lima, 1941.

GARCÍA JoRDÁn, Pilar, Cruz y arado, fusiles y discursos. La construcción de los Orientes en el Perú y Bolivia 1820-1940, IFEA, IEP, Lima, 2001.

- Iglesia y poder en el Perú contemporáneo 1821-1919, Cusco, Centro de Estudios Regionales Andinos «Bartolomé de las Casas», sf.

GARCÍA Rosell, Ricardo, Conquista de la Montaña. Sinopsis de los descubrimientos, expediciones, estudios y trabajos llevados a cabo en el Perú para el aprovechamiento y cultura de sus Montañas, Lima, Tip. «La Prensa», 1905.

Heras, Julián, Colegio de Propaganda Fide de Ocopa, en Revista Peruana de Historia Eclesiástica, vol. 1, Cuzco, 1989, pp. 213-223.

LARRABURE Y CORREA, Carlos, Colección de leyes, decretos, resoluciones y otros documentos oficiales referentes al Departamento de Loreto, 18 tomos, Monumenta Amazónica, Iquitos (Perú), 2008.

Mercurio Peruano, Tomos V y IX, 1792-1793, edición facsimilar, Lima.

NúÑEZ, Estuardo (comp.), Colección Documental de la Independencia del Perú, tomo XXVII, vol. 4, Comisión Nacional del Sesquicentenario de la Independencia, Lima, 1973.

PADILla y ÁGUILA, José María, Exposición económico política documentada de los sucesos ocurridos en el gobierno eclesiástico, civil y militar de las provincias de Mainas, invadidas por los disidentes del Perú en los años de 1820 y 1821, Madrid, por don Antonio Fernández, 1823.

Pons Muzzo, Gustavo, Las fronteras del Perú (Historia de los límites), Lima, Iberia, 1961.

Porras Barrenechea, Raúl y Wagner de Reyna, Alberto, Historia de los Límites del Perú, Editorial Universitaria, Lima, 1981.

RAIMONDI, Antonio, Apuntes sobre la provincia litoral de Loreto, Lima, Tipografía Nacional, por Manuel D. Cortés, 1862.

Ramírez Horton, Susan, Al servicio de Dios y de su Majestad. Los orígenes de las escuelas públicas para niños indígenas en el norte del Perú en el siglo XVIII, Lima, Asamblea Nacional de Rectores, 2014.

SÁNCHEZ RANGEL, Hipólito, Fragmentos de una pastoral escrita en Mainas en la fuga de su primer obispo, Madrid, Imprenta de E. Aguado, 1825.

- Pastoral religioso-política, geográfica, Imprenta de Pujol, Lugo, 1827.

VARGas UGARTE, Rubén, D. Baltasar Jaime Martínez de Compañón, obispo de Trujillo, en VARGAS UGARTE, Rubén, Tres figuras señeras del episcopado americano, Lima, Milla Batres, 1966, pp. 165-229.

VARGAS UGARTE, Rubén, El episcopado en los tiempos de la emancipación sudamericana, Lima, Librería e Imprenta Gil, 1962.

- Historia de la Iglesia en el Perú, vol. V, Imprenta de Aldecoa, Burgos, 1962.

Zubiate ZabARBURU, Alejandro, Contribución de Chachapoyas a la revolución emancipadora del Perú/ 1821-1824, Lima, 1974. 
TRES EJEMPLOS DE EDUCACIÓN POLITIICA: ANTIGÜEDAD CLÁSICA, AGUSTINISMOY ANTIMAQUIAVELISMO INGLÉS 
